\title{
Elaborating and Discoursing the Ethics in eHealth in the Philippines: Recommendations for Health Care Practice and Research
}

\author{
Martha Jane Pauline S. Umali, ${ }^{1,2}$ Alyssa Marie A. Evangelista-Sanchez, ${ }^{1}$ Jinky Leilanie Lu ${ }^{1,3}$ \\ Arturo M. Ongkeko Jr., ${ }^{1}$ Patrick G. Sylim, ${ }^{1}$ Abby Dariel F. Santos, ${ }^{1}$ Jonathan G. Fabia, ${ }^{1}$ \\ Portia H. Fernandez-Marcelo ${ }^{1}$ and Paul Matthew D. Pasco ${ }^{1,4}$ \\ ${ }^{1}$ National Telehealth Center, National Institutes of Health, University of the Philippines Manila \\ ${ }^{2}$ Department of Family and Community Medicine, College of Medicine and Philippine General Hospital, University of the Philippines Manila \\ ${ }^{3}$ College of Arts and Sciences, University of the Philippines Manila \\ ${ }^{4}$ Department of Neurosciences, College of Medicine and Philippine General Hospital, University of the Philippines Manila
}

\begin{abstract}
Objectives. The objectives of the research study were to determine ethical guidelines and principles applicable in the practice and research of eHealth and telehealth in the Philippines, how these are applicable to the Philippines, and to differentiate between the ethical issues in research and in clinical practice of eHealth.

Methods. This research study used: 1) review of ethics manuscripts, guidelines and literature; 2) focused group discussion and key informant interviews of experts; and 3) triangulation. The information sought for the review were- 1) relevant policies, guidelines in eHealth that are pertinent to the discussion of eHealth ethics in the Philippines; 2) components of ethics in eHealth research; and 3) components of ethics in eHealth practice. The framework of the consultation with experts was to identify mechanisms and strategies in incorporating ethics in both eHealthpractice and eHealth research within the following- 1) in reference to existing laws, policies, and guidelines on ethics in medicine and health; and 2) in the context of the Philippine setting.
\end{abstract}

Results. Based on the review, there are pertinent codes of ethics, applicable laws, policies and guidelines in eHealth, both in the international and local settings. The focus group discussion and key informant interview with experts yielded significant and deeper understanding on how to address the gaps and lapses of ethics applied to eHealth in the country. These recommendations were given which distinguish between the ethics in clinical practice and ethics in the planning and implementation of eHealth systems. There is also a need to resolve the problem of whose primary responsibility the patient is- the referring, commonly referred to as the attending

Corresponding author: Martha Jane Pauline S. Umali MD

National Telehealth Center

National Institutes of Health

University of the Philippines Manila

3rd Floor IT Complex, Philippine General Hospital

Taft Ave., Ermita, Manila 1000 Philippines

Telephone: +632 5091003

Email: martha.umali@telehealth.ph physician in the local community, or the specialist from the center. The proposed resolution was also presented.

Conclusion. The study has shown how important eHealth in potentially promoting timely and improved health care access. However, there are still lapses and gaps in the implementation of policies and guidelines on and relating to eHealth in the Philippines as shown by the data culled from the review and the focus group discussions with the experts. With more specific ethical guidelines and relevant policies, the development and practice of eHealth and telehealth will be on its way in bridging the gap and aiding in health systems development in the Philippines, especially with the support of the national government and collaboration of various agencies and stakeholders.

Key Words: ethics, eHealth, telehealth, telemedicine, Philippines

\section{Introduction}

The transfer of electronic health information, potentially with patient identifiers, poses a true challenge in health care in this information age. Even as eHealth and telehealth have been shown to be useful, its practice is not without any issue due to certain ethical issues such as patients' safety, privacy and confidentiality, duty of care, primary responsibility and accountability for patients enrolled in telemedicine, and offering health services from a distance over the internet. There are also issues about the eHealth system safety and reliability, professional accountability, technical standards in the management of clinical data, copyright, authorization and regulation, and licensing of telemedicine. ${ }^{1}$

Electronic Health or eHealth is defined by the World Health Organization as the transfer of health resources and health care by electronic means covering three main areas of eHealth which are health information delivery, public health services, and health systems management. ${ }^{2}$ It is fast emerging as an enabling strategy to provide better access to care, and tool to achieve better equity in health among communities, especially in resource poor settings and geographically isolated and disadvantaged areas (GIDA). Essentially, eHealth allows for better management of health information within the premise that better information leads to better health 
Although eHealth can provide compelling solutions to many of our country's health challenges, several ethical and legal issues must be considered.

Telehealth, which is an application of eHealth, is the use of information and communication technology (ICT) for surveillance, health promotion, health care and public health functions over a distance. It is broader and more expansive than the personal health nature of telemedicine, which uses telecommunication systems to diagnose and treat diseases and illnesses. ${ }^{2}$

\section{Why consider ethics in eHealth?}

Information and communications technology (ICT) has only been recently applied to health relative to other systems such as business, trade, economics, and communications. The main rationale for ICT is its cost effectiveness and efficiency which are important factors in the prioritization of programs of governments and institutions. Some ethical and legal issues, however, may arise in the ICT-integration of the health care system which pertains to the various stakeholders in eHealth including patients, health care professionals, health care informatics professional, soft and hardware providers, and outsourced eHealth providers. All these come into play in evaluating the totality of ICT in health care delivery.

"eHealth"is premised on an overarching principle of greater coverage for healthcare of the greater number of people, and hence anchored on the principles of justice, fairness, and right. Given this common understanding, however, there is a danger of falling into the dilemma of taking out the ethical and legal requirements of health informatics. In consideration of such dilemma, this paper shows the ethical processes as well as more ethical issues of eHealth in the Philippines. There is also the implication that eHealth should be readily accepted by any system and society due to these principles in whatever social, cultural and political context. However, a deeper understanding requires contextualizing the application and implementation of eHealth to consider specific and unique milieu.

Given the above, the objectives of the research study were to determine ethical guidelines and principles applicable in the practice and research of eHealth and telehealth in the Philippines, how these are applicable to the Philippines, and to differentiate between the ethical issues in research and in clinical practice of eHealth.

\section{Methods}

This research study used several methods to answer the above stated objectives. These were: 1) review of ethics manuscripts, guidelines and literature; 2) focused group discussion and key informant interviews of experts; and 3) triangulation using both 1 and 2 .

In the focus group discussion, certain points of discussion included ethical guidelines and principles applicable in the practice of eHealth and Telehealth, as well as discussions between ethical experts and the practitioners and implementers of Telehealth on how these guidelines and issues are and/or should be applied, customized, or modified in the Philippine setting.

The review was a literature search of relevant guidelines, policies and laws on eHealth and its various components through both document searches and internet resources. The information sought for the review were- 1) relevant policies, guidelines in eHealth that are pertinent to the discussion of eHealth ethics in the Philippines; 2) components of ethics in eHealth research; and 3) components of ethics in eHealth practice.

The framework of the consultation with experts was to identify mechanisms and strategies in incorporating ethics in both eHealth practice and eHealth research within the following- 1) in reference to existing laws, policies, and guidelines on ethics in medicine and health; and 2) in the context of the Philippine setting.

\section{Results}

Following the creation of the Philippine Health Research Ethics Board (PHREB) by the Philippine National Health Research System (PNHRS), ethical guidelines and principles in research have been established and regularly updated with the latest National Ethical Guidelines for Health Research (NEGHR) revised in 2011. The components of research ethics generally include provisions for the following: informed consent, risks, benefits and safety, termination of study/premature termination or suspension of trials, community care, privacy and confidentiality, disclosure of research results, standard of care, compensation of research participants, participation of groups that require special consideration, and absence of direct benefit. ${ }^{3}$

The World Medical Association (WMA) General Assembly in $2009^{4}$ has also laid out the Guiding Principles for the Use of Telehealth for the Provision of Health Care. These guiding principles stipulate that telehealth physicians must have adequate knowledge of the technology and appropriate skills in telehealth communication that incorporates protection of patient confidentiality as in common practice. Proper orientation of patients on telehealth must also be given prior to obtaining informed consent, in the same way as other health services, with further information as to who has responsibility or duty of care. ${ }^{4}$

The guidelines used in eHealth and telehealth convey adherence to principles of medical ethics, together with other healthcare professionals and workers. However, these guidelines remain merely as basic codes and principles of ethics that are insufficient in the implementation of eHealth in the Philippines. Thus, there is a need for the development of national policies and further international agreements on eHealth and telehealth with particular emphasis on ethics. Based on the RTD and review of policies and documents, the 
Table 1. International Laws, Policies and Guidelines in eHealth and their Stipulations

\begin{tabular}{|c|c|c|}
\hline $\begin{array}{c}\text { Laws, Policies and } \\
\text { Guidelines in eHealth }\end{array}$ & $\begin{array}{l}\text { Description of the Act in } \\
\text { Relation to eHealth }\end{array}$ & Certain Provisions of the Act \\
\hline $\begin{array}{l}\text { WMA Declaration of Helsinki } \\
\text { - Ethical Principles for } \\
\text { Medical Research Involving } \\
\text { Human Subjects } 2013^{5}\end{array}$ & $\begin{array}{l}\text { The World Medical Association } \\
\text { (WMA) has developed the } \\
\text { Declaration of Helsinki as a } \\
\text { statement of ethical principles for } \\
\text { medical research involving } \\
\text { human subjects, including } \\
\text { research on identifiable human } \\
\text { material and data. }\end{array}$ & $\begin{array}{l}\text { The Declaration of Geneva of the WMA binds the physician with the words, "The } \\
\text { health of my patient will be my first consideration," and the International Code of } \\
\text { Medical Ethics declares that, "A physician shall act in the patient's best interest when } \\
\text { providing medical care." } \\
\text { It is the duty of the physician to promote and safeguard the health, well-being and } \\
\text { rights of patients, including those who are involved in medical research. The } \\
\text { physician's knowledge and conscience are dedicated to the fulfillment of this duty. }\end{array}$ \\
\hline $\begin{array}{l}\text { WMA International Code of } \\
\text { Medical Ethics } 2006^{6}\end{array}$ & $\begin{array}{l}\text { Embodies and reiterates the code } \\
\text { of medical ethics }\end{array}$ & $\begin{array}{l}\text { There are three domains which are- duties of a physician in general, duties of a } \\
\text { physician to patients, and duties of physicians to colleagues. } \\
\text { Related to ethics is the policy that respects a patient's right to confidentiality. It is ethical } \\
\text { to disclose confidential information when the patient consents to it or when there is a } \\
\text { real and imminent threat of harm to the patient or to others and this threat can be only } \\
\text { removed by a breach of confidentiality }\end{array}$ \\
\hline $\begin{array}{l}\text { WMA Guiding Principles for } \\
\text { the Use of Telehealth for the } \\
\text { Provision of Health Care } 2009^{4}\end{array}$ & Defines the ethics of telehealth. & $\begin{array}{l}\text { A broader telehealth definition brings into play the entire range of activities that } \\
\text { support the patient and the public in being healthy: prevention, promotion, diagnostics } \\
\text { self-care and treatment are all areas where physicians play an important role. It is this } \\
\text { broader definition that the WMA endorses. } \\
\text { Covers guiding principles in eHealth such as duty of care, communications with } \\
\text { patients, patients' confidentiality, among others. }\end{array}$ \\
\hline $\begin{array}{l}\text { WMA Statement on the Ethics } \\
\text { of Telemedicine } 2007^{7}\end{array}$ & $\begin{array}{l}\text { Ethical guidelines when } \\
\text { practicing telemedicine. }\end{array}$ & $\begin{array}{l}\text { Reiteration of the WMA Guiding Principles for the Use of Telehealth for the Provision } \\
\text { of Health Care } 2009^{7}\end{array}$ \\
\hline eHealth Ethics Initiative $2000^{8}$ & $\begin{array}{l}\text { Ethical Issues for Internet } \\
\text { Healthcare: The eHealth Code of } \\
\text { Ethics }\end{array}$ & $\begin{array}{l}\text { Ethics standards and guidelines for Internet health sites are being developed and } \\
\text { promoted by several organizations and quasigovernment agencies. }\end{array}$ \\
\hline $\begin{array}{l}\text { WHO Executive Board } 115^{\text {th }} \\
\text { Session on eHealth } 2004 \text { and } \\
\text { the } 58^{\text {th }} \text { World Health } \\
\text { Assembly Report on eHealth } \\
2005^{9}\end{array}$ & $\begin{array}{l}\text { WHO's draft on strategy for } \\
\text { eHealth that would serve as the } \\
\text { basis for coordinating both } \\
\text { eHealth policies internationally } \\
\text { and WHO's activities on eHealth }\end{array}$ & $\begin{array}{l}\text { Ethical issues concern all countries in respect of confidentiality of information, dignity, } \\
\text { and privacy. Respect for the principles of equity is vital, considering differences in } \\
\text { culture, education, language, geographical location, physical and mental ability, age } \\
\text { and sex. Information and communication technologies should maximize the use of } \\
\text { scarce resources, rather than divert resources from meeting people's basic health needs. }\end{array}$ \\
\hline
\end{tabular}

following guidelines on ethics in eHealth and telehealth are thus formulated and proposed. These are general and specific guidelines on eHealth and telehealth service, practice and research.

\section{Results of the review of documents}

There are pertinent codes of ethics, applicable laws, policies and guidelines in eHealth. A summary of these are shown in Table 1 (international guidelines), and Table 2 (local guidelines).

The above laws, policies and guidelines cover various aspects and components of ethics in eHealth as shown in Table 3. These various components are categorized into three- ethical issues relating to the impact of eHealth on communities and populations, ethical issues in eHealth practice and patient care, and ethical issues in eHealth research.

\section{Results of the FGD key informant interview of experts}

The focus group discussion and key informant interview with experts yielded significant and deeper understanding on how to address the gaps and lapses of ethics applied to eHealth in the country. These recommendations are shown in Tables 4 and 5, which distinguish between the ethics in clinical practice and ethics in the planning and implementation of eHealth systems.

Table 4 shows the recommendations related to the impact of eHealth while Table 5 shows those related to patient care practice and research.

There is also a need to resolve the problem of whose primary responsibility the patient is- the referring, commonly referred to as the attending physician in the local community, or the specialist from the center. The proposed resolution is shown in Table 6.

"eHealth" research is now increasingly being pursued, and other issues of concern were also pointed out in the FGD and key informant interviews (Table 7).

\section{Discussion}

There were salient data and points for consideration culled from the review of documents and the primary data gathering through FGD and interviews of experts. The basic components of ethics should be considered in the overall impact of eHealth to underserved populations for the cause of justice, respect, fairness and rights, and cost-efficiency. 
Elaborating and Discoursing the Ethics in eHealth in the Philippines

Table 2. Local Laws, Policies and Guidelines in eHealth and their Stipulations

\begin{tabular}{|c|c|c|}
\hline $\begin{array}{c}\text { Laws, Policies and } \\
\text { Guidelines in eHealth }\end{array}$ & Description of the Act in Relation to eHealth & Certain Provisions of the Act \\
\hline $\begin{array}{l}\text { The Medical Act of } 1959 \\
\text { (RA 2382) }^{10}\end{array}$ & $\begin{array}{l}\text { This Act provides for and shall govern the } \\
\text { supervision, control and regulation of the } \\
\text { practice of medicine in the Philippines, among } \\
\text { others }\end{array}$ & $\begin{array}{l}\text { Code of Ethics as approved by the Philippine Medical Association shall be } \\
\text { carried out. }\end{array}$ \\
\hline $\begin{array}{l}\text { Professional Regulation } \\
\text { Commission (PRC) Board } \\
\text { of Medicine Code of } \\
\text { Ethics }^{11}\end{array}$ & $\begin{array}{l}\text { Embodies the code of ethics of medical practice } \\
\text { including ethics concerning patient-physician } \\
\text { relationship. }\end{array}$ & $\begin{array}{l}\text { Among which are: 1) Informed consent must be obtained from the patient } \\
\text { by the physician; 2) If patient is not capable for any reason, the informed } \\
\text { consent shall be obtained from a spouse or an immediate relative; and 3) The } \\
\text { privacy and confidentiality of patients is utmost even after death except } \\
\text { when required in the promotion of justice, safety and public health. }\end{array}$ \\
\hline $\begin{array}{l}\text { Philippine Medical } \\
\text { Association Code of } \\
\text { Ethics }^{12}\end{array}$ & $\begin{array}{l}\text { Embodies the code of ethics of medical practice } \\
\text { including ethics concerning patient-physician } \\
\text { relationship }\end{array}$ & $\begin{array}{l}\text { Same as the Professional Regulation Commission (PRC) Board of } \\
\text { Medicine Code of Ethics }{ }^{11}\end{array}$ \\
\hline $\begin{array}{l}\text { Data Privacy Act of the } \\
\text { Philippines } 2012 \\
(\text { RA 10173) }\end{array}$ & $\begin{array}{l}\text { An Act to ensure that personal information in } \\
\text { information and communications systems in the } \\
\text { government and in the private sector are } \\
\text { secured and protected, }\end{array}$ & $\begin{array}{l}\text { Ensure privacy of persons (including patients), and data protection. } \\
\text { This Act also mandates compliance of personal information controllers with } \\
\text { the provisions of the data privacy, including institutions, data handlers, } \\
\text { information processor, and outsourced enterprises handling data. } \\
\text { Data processing is defined in this the collection, recording, organization, } \\
\text { storage, updating or modification, retrieval, consultation, use, } \\
\text { consolidation, blocking, erasure or destruction of data. }\end{array}$ \\
\hline $\begin{array}{l}\text { eCommerce Act of } 2000 \\
(\text { RA 8792) }\end{array}$ & $\begin{array}{l}\text { The Act stipulates the need to create an } \\
\text { information-friendly environment which } \\
\text { supports and ensures the availability, diversity } \\
\text { and affordability of ICT products and services } \\
\text { (including health) }\end{array}$ & $\begin{array}{l}\text { Included in the legal provision is the need to develop institutional policy } \\
\text { changes and human resources capable of operating and utilizing } \\
\text { electronic appliances and computers; its obligation to facilitate the } \\
\text { transfer and promotion of technology; and to ensure network security, } \\
\text { among others. }\end{array}$ \\
\hline $\begin{array}{l}\text { PHREB National Ethical } \\
\text { Guidelines for Health } \\
\text { Research } 2011^{3}\end{array}$ & $\begin{array}{l}\text { A review and update the existing ethics } \\
\text { guidelines by the National Ethics Committee } \\
(1995,1996,2000) \text { and the Technical Working } \\
\text { Group on Ethics (2006) to ensure adherence to } \\
\text { universal ethical principles and values as well as } \\
\text { respect for Filipino values and culture. }\end{array}$ & $\begin{array}{l}\text { Philippine institutions that engage in biomedical and behavioral research } \\
\text { shall establish an Institutional Ethics Review Committee which shall } \\
\text { provide independent, competent, and timely review of the ethics of the } \\
\text { proposed studies. }\end{array}$ \\
\hline
\end{tabular}

Table 3. Aspects and Components of Ethics in eHealth Issues

\begin{tabular}{ll}
\hline Major Categories & Specific Components \\
\hline Ethical issues relating to & Justice \\
the impact of eHealth on & eHealth's reach to underserved communities \\
communities and & The socio-cultural dimension in ethics \\
populations & Ethics in eHealth and Telehealth Proposals and \\
& Protocols for Review \\
Ethical issues in eHealth & Duty of Care \\
practice and patient care & Management plan for treatment \\
& Knowledge of healthcare \\
& Standards and Quality of Care \\
& Competence, training and education as integral \\
& to ethics \\
& Protection of privacy and confidentiality \\
Ethical issues in eHealth & Informed Consent \\
research & Privacy and Confidentiality \\
& Vulnerability and Risks \\
& Autonomy and respect for persons \\
& Beneficence \\
& Non-maleficence \\
& Medical Devices \\
& Compensation of Research Participants \\
& Disclosure of Research Results \\
& After Care \\
\hline
\end{tabular}

There is also a distinction between eHealth healthcare practice and eHealth research, as well as the role between the referring physician in the local community and the specialist in the center. A discursive elaboration is shown below.

In health care practice and research, the fundamental ethical principles of autonomy and respect for persons, beneficence, non-maleficence and justice must always be observed in the planning and implementation of eHealth programs, projects and research protocols. ${ }^{5}$ In general, vulnerable persons and groups must not be included unless the program or research is necessary to promote the health of the population represented or it cannot be implemented in non-vulnerable populations. In that case, special consideration and protection must be carried out including further assistance and provision of adequate information prior to obtaining informed consent and at every phase of implementation. ${ }^{3}$ Likewise, prioritizing geographically isolated and disadvantaged areas (GIDAs) reflects a sense of justice by giving the advantage of better health information and technology to those who might not have access 
Elaborating and Discoursing the Ethics in eHealth in the Philippines

Table 4. Recommendations for Ethics in eHealth in the Philippines in Relation to the Impact of eHealth

\begin{tabular}{|c|c|c|}
\hline $\begin{array}{l}\text { Important Ethical } \\
\text { Issues in eHealth }\end{array}$ & Ethical Issues in Clinical Practice & Ethical Issues in the Planning and Implementation of eHealth systems \\
\hline Justice & $\begin{array}{l}\text { Clinical specialists refer physicians in remote areas } \\
\text { who have gained training on managing uncommon } \\
\text { and difficult conditions. }\end{array}$ & $\begin{array}{l}\text { Prioritizing geographically isolated and disadvantaged areas (GIDAs). } \\
\text { Facilitation of the referral system through telehealth. }\end{array}$ \\
\hline \multirow[t]{2}{*}{$\begin{array}{l}\text { eHealth's reach to } \\
\text { underserved } \\
\text { communities }\end{array}$} & $\begin{array}{l}\text { Patients in far-flung areas, or underserved populations } \\
\text { should be attended to by the health infrastructure } \\
\text { including pool of health professionals. }\end{array}$ & $\begin{array}{l}\text { eHealth programs are user-friendly and meaningful, and could be easily } \\
\text { integrated into the current system for its improvement and sustainability. }\end{array}$ \\
\hline & $\begin{array}{l}\text { Encourage patients to participate in their treatment } \\
\text { protocol or choice of procedure even through eHealth. }\end{array}$ & $\begin{array}{l}\text { Encouraging involvement of patients and/or patient advocate groups in the } \\
\text { design, implementation and evaluation of eHealth and telehealth technologies, } \\
\text { and deployment programs is suggested. }\end{array}$ \\
\hline \multirow[t]{2}{*}{$\begin{array}{l}\text { The socio-cultural } \\
\text { dimension in ethics }\end{array}$} & $\begin{array}{l}\text { Health providers must consider spiritual beliefs and } \\
\text { socio-cultural practices in their approach to the health } \\
\text { of patients. }\end{array}$ & $\begin{array}{l}\text { The socio-cultural dynamics of local communities must always be given emphasis } \\
\text { mainly because they may be considered vulnerable participants. }\end{array}$ \\
\hline & & $\begin{array}{l}\text { There is a need for social preparation and community consultation before even } \\
\text { introducing telehealth. }\end{array}$ \\
\hline
\end{tabular}

Table 5. Recommendations for Ethics in eHealth in the Philippines in Relation patient care Practice and Research

\begin{tabular}{|c|c|}
\hline $\begin{array}{l}\text { Important Ethical } \\
\text { Issues in eHealth }\end{array}$ & Ethical Issues in Clinical Practice \\
\hline $\begin{array}{l}\text { Autonomy and } \\
\text { respect for persons }\end{array}$ & $\begin{array}{l}\text { In general, vulnerable persons and groups must not be } \\
\text { included unless the program is necessary to promote } \\
\text { the health }\end{array}$ \\
\hline \multirow[t]{2}{*}{ Beneficence } & The medical treatment should benefit the patient. \\
\hline & $\begin{array}{l}\text { The health and safety of patient is utmost in the } \\
\text { treatment protocol, and should be above any financial } \\
\text { gains. }\end{array}$ \\
\hline \multirow[t]{2}{*}{ Non-maleficence } & $\begin{array}{l}\text { Adverse risks should be avoided or minimized during } \\
\text { the treatment of the patient. }\end{array}$ \\
\hline & $\begin{array}{l}\text { There should be no fraud or undue influence on the } \\
\text { type of treatment or drugs that patients opt to } \\
\text { choose/adopt. }\end{array}$ \\
\hline $\begin{array}{l}\text { Competence, training } \\
\text { and education as } \\
\text { integral to ethics }\end{array}$ & $\begin{array}{l}\text { Telehealth physicians must have adequate education of } \\
\text { the technology and appropriate skills in telehealth } \\
\text { communication that incorporates protection of patient } \\
\text { confidentiality as in common practice. }\end{array}$ \\
\hline \multirow[t]{2}{*}{$\begin{array}{l}\text { Protection of privacy } \\
\text { and confidentiality }\end{array}$} & $\begin{array}{l}\text { There is implied patient informed consent in } \\
\text { consultations of patients. }\end{array}$ \\
\hline & $\begin{array}{l}\text { There is stipulated confidentiality of information even } \\
\text { after death of patient unless required by law and such } \\
\text { information shall not be divulged by the physician. }\end{array}$ \\
\hline \multirow[t]{2}{*}{ Informed consent } & $\begin{array}{l}\text { There is implied patient informed consent in } \\
\text { consultations of patients. }\end{array}$ \\
\hline & $\begin{array}{l}\text { There is stipulated confidentiality of information even } \\
\text { after death of patient unless required by law and such } \\
\text { information shall not be divulged by the physician. }\end{array}$ \\
\hline
\end{tabular}

\section{Ethical Issues in the Planning and Implementation of eHealth systems}

Vulnerable persons and groups must not be included too.

Community participation is encouraged to uphold their autonomy and prioritize their felt needs.

ICTs should maximize the use of scarce resources, rather than divert resources from meeting people's basic health needs.

Promote self-empowerment and development of communities on health needs.

Injury or any adverse reaction from treatment should be prevented.

There should be a provision on handling adverse effects that may arise during or after the research.

Coercion, intimidation and deception must not be done in obtaining consent.

All eHealth professionals, personnel and implementers must have adequate knowledge, proper attitudes and the required competencies prior to involvement in any eHealth program, project or research.

Respect, privacy and confidentiality through de-identification and other security measures must be strictly observed.

Processing of personal information especially sensitive personal information of all participants must be secured and kept confidential in adherence to the Data Privacy Act of 2012.13

Concerns on vulnerability and risks should be considered in the informed consent.

Obtain voluntary informed consent preferably in writing, from patient-study participant.

Voluntary informed consent must be secured, using appropriate language and communication, with full disclosure and statement of the means and intended purpose/s of electronic transmission and utilization of health data

Submission of proposals and protocols to research ethics bodies for review and approval. 
Elaborating and Discoursing the Ethics in eHealth in the Philippines

Table 6. Defining the Roles of the Referring Physician vs the Role of the Specialist

\begin{tabular}{|c|c|c|}
\hline Issues in eHealth & Role of Referring Physician & Role of Specialist \\
\hline Duty of Care & Main responsibility and duty of care for the patient. & Receives and gives the teleconsultation. \\
\hline Informed Consent & Secured primarily by the referring physician. & Specialist or consultant is advised on the treatment and ethics of treatment. \\
\hline $\begin{array}{l}\text { Management plan } \\
\text { for treatment }\end{array}$ & $\begin{array}{l}\text { The final management plan is done by the referring } \\
\text { physician. }\end{array}$ & $\begin{array}{l}\text { Updates and feedback on the patient's condition are encouraged to be sent to the } \\
\text { clinical specialists and the telehealth center. }\end{array}$ \\
\hline $\begin{array}{l}\text { Knowledge of } \\
\text { healthcare }\end{array}$ & $\begin{array}{l}\text { Attending physician must be prepared to refer the } \\
\text { patient for direct specialist consultation or for transfer } \\
\text { of care as appropriate }\end{array}$ & $\begin{array}{l}\text { Inputs from consultants/ experts are the best and fastest possible way, or are the } \\
\text { only alternative. }\end{array}$ \\
\hline $\begin{array}{l}\text { Privacy and } \\
\text { Confidentiality }\end{array}$ & $\begin{array}{l}\text { Referring physician ensures privacy and } \\
\text { confidentiality of patient's information. }\end{array}$ & $\begin{array}{l}\text { Privacy is ensured in transmission and receipt of electronic health data in the } \\
\text { center, to the clinical specialist and back to the referring physician, data storage, } \\
\text { and statistical/epidemiological use. }\end{array}$ \\
\hline $\begin{array}{l}\text { Vulnerability and } \\
\text { Risks }\end{array}$ & $\begin{array}{l}\text { Referring physician addresses individual patient's } \\
\text { risk and vulnerabilities to the treatment protocol. }\end{array}$ & $\begin{array}{l}\text { Miscommunications between the referring physician and the telemedicine clinical } \\
\text { specialist resulting in misdiagnosis and mismanagement must be avoided. }\end{array}$ \\
\hline $\begin{array}{l}\text { Standards and } \\
\text { Quality of Care }\end{array}$ & $\begin{array}{l}\text { Referring physician adheres to clinical practice } \\
\text { guidelines and protocols. }\end{array}$ & $\begin{array}{l}\text { Continuous monitoring and improvement of telehealth services to achieve } \\
\text { targeted clinical outcomes. }\end{array}$ \\
\hline
\end{tabular}

Table 7. Additional Ethics Issues in eHealth Research

\begin{tabular}{|c|c|}
\hline Issues in eHealth Research & Stipulation/ Recommendation \\
\hline Medical Devices & $\begin{array}{l}\text { Clinical trials on medical devices must primarily show safety and performance according to its intended purpose. There } \\
\text { should be an expert consultant such as a bioengineer to review the research protocol. }{ }^{3}\end{array}$ \\
\hline $\begin{array}{l}\text { Compensation of Research } \\
\text { Participants }\end{array}$ & Appropriate and reasonable compensation for study participants must be given. ${ }^{3}$ \\
\hline Disclosure of Research Results & $\begin{array}{l}\text { Investigators and authors must adhere to ethical reporting of research results, and including all those involved in the } \\
\text { research project, must have ethical obligations in the publication and dissemination of results. }{ }^{3}\end{array}$ \\
\hline After Care & $\begin{array}{l}\text { In the event of study conclusion or termination, patient and community care must be extended as needed with particular } \\
\text { consideration for depressed communities, ethnic groups and those involving international collaborative protocols. }{ }^{3}\end{array}$ \\
\hline
\end{tabular}

otherwise. Referring physicians in remote areas are also somewhat gaining from informal training and education by the clinical specialists on managing uncommon and difficult conditions, and from facilitating the referral system through telehealth. These are affirmed in the bias for GIDA in the NTSP by the University of the Philippines with the DOH and DOST, and should continue to attain better equity in health care.

ICTs should maximize the use of scarce resources, rather than divert resources from meeting people's basic health needs. Community participation must be encouraged to uphold their autonomy and prioritize their felt needs, and to promote self-empowerment and development of communities. This is also to ensure that eHealth programs are user-friendly and meaningful, and could be easily integrated into the current system for its improvement and sustainability. The involvement of patients and/or patient advocate groups in the design, implementation and evaluation of eHealth and telehealth technologies and deployment programs is suggested.

In relation to competence of eHealth professionals, personnel and implementers must have adequate knowledge, proper attitudes and the required competencies prior to involvement in any eHealth program, project or research.
These guiding principles affirm that telehealth physicians must have adequate education of the technology and appropriate skills in telehealth communication that incorporates protection of patient confidentiality as in common practice. There should be a requirement to earn a certificate of training and orientation prior to involvement in eHealth and telehealth, and for regular continuing training seminars (for example, every 3 years) in order to remain qualified to continue eHealth/telehealth practice. Furthermore, the training program must be attended by all physicians and other professionals involved in eHealth/telehealth programs and projects, with particular consideration to non-medical personnel and implementers. eHealth education and training must not only include adequate education of the technology and appropriate skills in telehealth communication, but must also have a devoted time for the ethical aspect and considerations in eHealth and telehealth with emphasis on the rights and welfare of patients and participants, cooperation with and respect for all who are engaged in eHealth and telehealth, and confidentiality of personal and health information.

Respect, privacy and confidentiality through deidentification and other security measures must be strictly observed. Processing of personal information especially 
sensitive personal information of all participants must be secured and kept confidential in adherence to the Data Privacy Act of 2012.13 Private and confidential information must never be divulged except when required in the interest of justice, public health and public safety ${ }^{11}$ or when with a voluntary informed consent from the patient/participant.

There is also the socio-cultural consideration in eHealth. The socio-cultural dynamics of local communities must always be given emphasis mainly because they may be considered vulnerable participants and their involvement must always be in accordance with their spiritual beliefs and socio-cultural practices. The ethical considerations should take into account the community's set values, traditional beliefs and practices regarding health, including their idea of a good doctor and a good health system. Balance established roles and worth of local physicians in their communities with the objective of the program to improve health care delivery to patients. Through social preparation, community consultation and getting the pulse of the locale including the local physicians before even introducing telehealth, concerns on vulnerability and risks may be minimized or prevented.

For securing informed consent, in general and as applicable, all the elements have to be covered in obtaining voluntary informed consent preferably in writing, and by the physician, investigator or another qualified individual when taking caution with possible dependent relationships such as between a physician-investigator and a patient-study participant. Voluntary informed consent must be secured, using appropriate language and communication, with full disclosure and statement of the means and intended purpose/s of electronic transmission and utilization of health data (including diagnostics results, imaging studies, photos, etc.), which may be any of the following: for medical advice or opinion, documentation of rare cases, training and education, research, storage for future use, or other purposes. Aside from the patient or participant and a witness, consent and signatures of a child or minor's parent/s or legal guardian/s and those of an incapacitated adult's legally authorized representative/s must also be obtained. Coercion, intimidation and deception must not be done in obtaining consent. Emphasis must be given on protecting privacy and confidentiality of personal data and health information of every patient or participant. Moreover, information on how this will be addressed should be detailed.

Privacy and confidentiality of electronic health data (in the center, to the clinical specialist and back to the referring physician, as well as data storage, and statistical/epidemiological use) must also be ensured. Miscommunications between the referring physician and the telemedicine clinical specialist resulting in misdiagnosis and mismanagement must be avoided. All possible risks and vulnerability of participants must be anticipated, prevented and minimized.
Standards of practice using clinical practice guidelines and protocols should be followed to ensure quality of care that also entails continuous monitoring and improvement of telehealth services to achieve targeted clinical outcomes. ${ }^{4}$

The debate on the role of referring/attending physician to that of the specialist is also a tenuous area in eHealth. These have been defined so far in the recommendations. The referring physician such as a rural health physician or doctor-to-the-barrios (RHP or DTTB) maintains the doctorpatient relationship (not the clinical specialist who receives the teleconsultation), and has the responsibility and duty of care for the patient. ${ }^{7}$ Referring physicians must seek informed consent for any procedure or intervention that is planned for the patient including those for teleconsultations, so that the patient is aware that he/she is also receiving medical advice from a clinical specialist. Care must be taken to ward off impressions that the referring physician does not know what he is doing; but instead, is receiving inputs from experts in the best and fastest possible way in their situation. The final decision regarding the management plans rests on the attending physician after obtaining an informed consent from the patient. Updates and feedback on the patient's condition are encouraged to be sent to the clinical specialists and the Telehealth center. It must be emphasized that telehealth and telemedicine should only be performed when direct consultation would not be possible within an acceptable time period. Awareness of its limitations is also essential such that the attending physician must be prepared to refer the patient for direct specialist consultation or for transfer of care as appropriate.

The role of the clinical specialist is to advice the best practice guidelines and recommendations that are applicable to the setting where the teleconsultation came from based on the available data received, to ensure that medical advice and instructions are clearly communicated and well understood, to follow-up status and ensure continuity of care for patients, and to ask for feedbacks from referring physicians. The clinical specialist should keep a detailed record of the information received and the advice delivered to the referring physician. ${ }^{7}$

\section{Conclusion and Recommendations}

The study has shown how important eHealth is in potentially promoting timely and improved health care access. However, there are still lapses and gaps in the implementation of policies and guidelines on and relating to eHealth in the Philippines as shown by the data culled from the review and the focus group discussions with the experts.

The scope of and opportunities for eHealth are expanding such that there should be a mechanism to organize and regulate these emerging technologies for health. The establishment of laws such as House Bill No. 6336 or the Telehealth Bill was formulated for this effect, and as such, to institutionalize a National Telehealth System 
which should be well defined in terms of the principles of ethics in eHealth, including the mechanisms and strategies for achieving this.

All of the ethical considerations and guidelines that were presented above are vital in the implementation of ethical eHealth/telehealth programs and research projects. There should be advocacy to engage other government facilities in the National Telehealth Service Program for a more comprehensive healthcare system. This necessitates education and training of physicians, allied professionals and other participants in eHealth and telehealth. There is also a need to engage the other stakeholders and providers in eHealth such as the hardware and software providers, health informatics professionals, and outsourced business enterprises on ethics in eHealth.

It is further recommended that a framework on how to incorporate important ethical guidelines in eHealth be crafted which addresses both eHealth for practice and eHealth for research. For example, for eHealth for research, components should include social value and scientific validity. Social value covers aspects of ensuring that the research will address an important gap in the population being studied, and that the results will have the prospect of improving the lives of the subject respondents. Scientific value of the research ensures that the study design is rigorous and appropriate for the stated objectives. All these recommendations should also be reviewed by a competent ethics committee.

For eHealth practice, it is recommended that the highest mechanisms for the privacy of the consumers and data protection be guaranteed. Hence, a governmental regulatory body should be created in consultation with major agencies, and come up with institutional arrangements and governance framework for ownership and access to data, custodianship, and responsibility and accountability. As yet, there is still a long way to go, and this research is one earlier means to achieving a more comprehensive and integrated ethics in eHealth.

\section{Acknowledgments}

We express our gratitude to all participants of the RTD who have significantly contributed content for this paper by providing their comments, reviews and recommendations, particularly the ethics experts: Dr. Evangeline Olivar-Santos, Dr. Marcelito Durante, Dr. Prospero Ma. Tuaño, Dr. Concesa Padilla, and Dr. Harvy Joy Liwanag. We thank the partners of NTHC who participated: representative officials from the DOH - BLHD Ms. Teresita Guzman and Ms. Marifel Santiago, and consultant from the DOST ICTO Mr. Al Alegre; Telemedicine Clinical Specialists from UP ManilaPGH Dr. Lorna Abad and Dr. Ma. Cecilia Lim, and from BGHMC Dr. Ricardo Briones Runez, Jr. and Dr. Ray Suanding; and our PHN partner from Peñarrubia, Abra Mr. Antonio Japson. We also thank Dr. Jeriel de Silos for initially organizing the RTD. Lastly, to all the NTHC staff and our other partners in eHealth and telehealth, especially in GIDAs, maraming salamat po!

\section{References}

1. Rezende EJ, Melo Mdo C, Tavares EC, Santos Ade F, Souza Cd. Ethics and eHealth: reflections for a safe practice. Rev Panam Salud Publica. 2010; 28(1):58-65.

2. World Health Organization.e-health [Online]. 2014 [cited 2015 Aug] Available from http://www.who.int/trade/glossary/story021/en.

3. PHREB NEGHR. PHREB Ad Hoc Committee for the Revision of the Ethical Guidelines National Ethical Guidelines for Health Research. Philippine National Health Research System. 2011.

4. World Medical Association. Statement on Guiding Principles for the Use of Telehealth for the Provision of Health Care [Online]. 2009 [cited 2015 Aug]. Available from http://www.wma.net/en/30publications/ 10policies/t5.

5. World Medical Association.Declaration of Helsinki: Ethical Principles for Medical Research Involving Human Subjects [Online]. 2013 [cited 2015 Aug]. Available from http://www.wma.net/en/30publications/10 policies/b3.

6. World Medical Association.International Code of Medical Ethics [Online]. 2006 [cited 2015 Aug]. Available from http://www.wma.net/ en/30publications/10policies/c8.

7. World Medical Association. Statement on the Ethics of Telemedicine [Online]. 2007 [cited 2015 Aug]. Available from http://www.wma. net/en/30publications/10policies/t3.

8. RippenH,Risk A.eHealth Ethics Initiative. Journal of Medical Internet Research [Online]. 2000 [cited 2015 Aug]. Available fromhttp://www. ncbi.nlm.nih.gov/pmc/articles/PMC1761853.

9. World Health Organization.eHealth Resolution [Online]. 2005 [cited 2015 Aug]. Available from http://www.who.int/healthacademy/news/en.

10. Medical Act.The Medical Act of 1959 or RA 2382 [Online]. 1959 [cited 2015 Aug]. Available from http://www.prc.gov.ph/uploaded/ documents/MEDICAL\%20LAW.pdf.

11. Professional Regulation Commission. Philippine Board of Medicine Code of Ethics [Online]. 1959 [cited 2015 Aug]. Available from http://www.prc.gov.ph/uploaded/documents/Board\%20of\%20MedicineCE.pdf.

12. Philippine Medical Association. Code of Ethics [Online]. 2008 [cited 2015 Aug]. Available from https://www.philippinemedicalassociation.org/ downloads/pma-codes/FINAL-PMA-CODEOFETHICS2008.pdf.

13. Data Privacy Act. Data Privacy Act or Republic Act 10173 [Online]. 2012 [cited 2015 Aug]. Available from http://www.gov.ph/2012/08/15/ republic-act-no-10173.

14. eCommerce Act.eCommerce Act or RA 8792 [Online]. 2000 [cited 2015 Aug]. Available from http://www.pctc.gov.ph/initiatv/ RA8792.htm. 